\title{
Media: A Double-Edged Sword in the Disease Control. Content Analysis of News Report on SARS Event in Taiwan
}

\author{
Shiow-Ing Wang1* ${ }^{*}$ Chih-Liang Yaung ${ }^{2}$, Hung-En Liao², Hung-Che Chiang1 \\ ${ }^{1}$ National Environmental Health Research Center, National Health Research Institutes, Miaoli, Taiwan \\ ${ }^{2}$ Department of Healthcare Administration, College of Health Science, Asia University, Taichung, Taiwan \\ Email: ${ }^{*}$ shiowing@nhri.org.tw
}

Received 8 May 2014; revised 23 June 2014; accepted 10 July 2014

Copyright (C) 2014 by authors and Scientific Research Publishing Inc.

This work is licensed under the Creative Commons Attribution International License (CC BY).

http://creativecommons.org/licenses/by/4.0/

(c) (i) Open Access

\begin{abstract}
Objective: This study was conducted to explore what media exactly do when disease is emerging and furthermore, to infer the role and the responsibility that media should play. Method: A content analysis with 0.81 inter-rater reliability was adopted to categorize SARS-related events shown on the three major newspapers in 117 days, dated from March 13th (the date before the first probable case of SARS in Taiwan was identified) to July 7 th (the date after Taiwan was removed from the list of SARS-affected countries by the bulletin of World Health Organization), 2003. Results: There were totally 8923 SARS events related news found in the observed newspapers during the study period. When the epidemic situation is more serious, the media will also lay out more coverage on reporting the related contents. In the reporting contents, the three most influential newspapers in Taiwan mainly emphasized the impact dimension (34.27\%). Only $2.16 \%$ of the coverage was on the topic of health communication and prevention education. Overall, the opinions of general public are the primary sources of news $(46.57 \%)$. Health authority was not the main and typical sources information of the press $(9.42 \%)$. Conclusion: Media is a double-edged sword in the communicable disease control. We suggest that the health authority should take advantage of media to transmit message rapidly to convey related information to public.
\end{abstract}

\section{Keywords}

Severe Acute Respiratory Syndrome (SARS), News Report, Media, Content Analysis

\footnotetext{
${ }^{*}$ Corresponding author.
} 


\section{Introduction}

The media had been called "Fourth Estate". It not only means that the media is powerful to influence the public but also means it has lots social responsibilities to take, such as monitoring, caring, educating, and entertaining [1]. Many studies have pointed out the importance of the media in disease control [2]-[8], but little is known about what media exactly do when disease is emerging. Thus, the present study intended to take the example of Severe Acute Respiratory Syndrome (SARS) strike in 2003, exploring the role of the media played in the disease control. Then discussing the responsibility of media should take in the prevention and controlling of disease. How health authority transforms obstacles of the media into benefits when the disease is striking is also elaborated.

Severe Acute Respiratory Syndrome, the first severe and readily transmissible new disease emerging in the 21st century, spreaded quickly and caused numerous deaths in the world [9]. Taiwan also suffered from the attack of SARS. The epidemic development in Taiwan could be divided into 2 distinct stages [10]. Stage I started from March 14, 2003, the date when the first case was identified, to mid-April. In this stage, probable cases had traceable contact with infected patients or traveling histories to affected areas. Consequently, Taiwan was classified as one of the limited local transmission areas. Stage II began on mid-April, when patients infected with SARS via intra-hospital or inter-hospital transmission without confirmed sources of infection. Thus, the World Health Organization placed Taiwan on the travel advisory list as one of the affected areas on May 21, 2003. As of July 5, 2003, statistics showed that there had been 674 diagnosed SARS cases and 84 patients died in Taiwan.

In the striking disaster, the most important thing is to keep the communication channel unimpeded through the process. Government has the responsibility to formulate policy, adopt related measures and deliver messages to health care workers as well as the public to win their cooperation and supports. During the outbreak war, health care workers should transmit the message about the needed resources or difficulties to the authorities and the rules requiring patients to abide by. The populace may express their concerns and feedback to the government and health care workers and fully cooperate with the prevention and control measures. In this communication process, the media played a very important role.

The media has potential capacity toward the public in educating health-related knowledge, shaping healthrelated beliefs and influencing health behavior [11]. According to the research [12] [13], media is the main channel of knowledge acquisition regarding SARS prevention and control measures needed to obey in Taiwan. However, the media is like a double-edged sword. Information disseminated through media is prompt and timely to raise public awareness of an impending disease, especially in such an outbreak of new transmissible disease. On the contrary, false reports or overstating negative news may also stir up public anxiety or panic [14] and expand negative impacts on social stability. Thus, in order to explore the role of media under such crisis, it is necessary to examine the content of media which is appropriate for their purpose.

Although the SARS epidemic has been under control, considering the possibility of future outbreaks to take precautions before it is too late, it is important to learn lessons from past experience. The occurrence of SARS in 2003 provides a good opportunity to understand where the media collect reporting materials from, how the media interpret SARS relevant events, who are the sources of information, and what the relationship between the news report and the development of SARS epidemic is. Thus, the aim of this study was to examine how the SARS event is displayed in the newspaper media, and turn the media from a stumbling block into a stepping stone in the disease control.

\section{Methods}

A content analysis was conducted to evaluate how the SARS event is displayed in the newspaper. Content analysis has been defined as a objective, systematic, and quantitative technique for compressing many words of texts into fewer content categories based on explicit rules of coding [15]-[17]. It enables researchers to sift through large volumes of data with relative ease in a systematic fashion [18].

\subsection{Material}

Newspapers were chosen in the study as materials due to their characteristics of depth, comprehensiveness, and they accommodate different voices and opinions. In addition, newspapers provide sufficient and traceable study materials. According to a survey conducted by AC Nielsen, there are three leading newspapers in Taiwan [19]: the China Post, the United Daily News, and Liberty Times, which were chosen in the study. For the study's 
purpose, each newspaper excluded the local news page, the ad page, the entertainment page, and the sports page layout.

The observed period of 117 days, from the date when the first probable case of SARS in Taiwan was identified to the date when Taiwan was removed from the list of SARS-affected countries (13 March 2003-7 July 2003), were analyzed.

\subsection{Unit of Analysis}

The coding unit used in this research was a news article identified by the author. First, we examined the title of news. If the "SARS" and related words appeared, news was selected into analyses. Each new was coded according to its content. If the news involved two or more issues, the main issue would be the basis for classification. In addition, we also interested in the frequency of SARS news displaying on the front page and the size arrangement. Therefore, we quadrisected a page to calculate the proportion of the SARS event news occupied on. In addition, the quoted source for each statement was recorded. The quoted source was classified into six categories: health authorities, local government, central ministries, health experts, general public, and foreign reports.

\subsection{Categorization}

Establishing coding categories is one of the most critical steps in the content analysis [20]. Categories had better be comprehensive and mutually exclusive. SARS was an international event, the interaction between international organization and countries was one of the important dimensions need to explore. In addition, SARS was an infectious disease. The progress of case control sent a critical message to the public regarding the severity to which how the disease had been spreading. In addition, preventive strategies and measures would be accompanied by awaking the public to comply with. SARS was a newly emerging disease, the impact of disease was still chaotically unclear when it occurred in 2003. Thus, it was worth to study the possible impacts. Eventually, based on the study purpose and the characteristics of addressed issue, coding categories were classified into "International interaction”, “Epidemic message”, “Control measures”, “Impact”, and “Others” five dimensions.

\subsection{Inter-Rater Reliability}

In this study, all collected newspaper was analyzed by two well-trained coders. It is widely acknowledged that inter-rater reliability is a critical component of content analysis [21]. Cohen's kappa was used to calculate interrater reliability as recommended by most scholars. One subsample of 18 newspapers was randomly selected for a reliability check. The inter-rater reliability was 0.81 which may be considered excellent agreement beyond chance [22] [23].

\section{Results}

There was a total 8923 news related to the SARS event found in the observed newspapers during the study period.

\subsection{Layout Occupying Rate and Epidemic Development}

There is a pas de deux style between the page layouts of "SARS event" report and the epidemic development. When the epidemic situation is more serious, the media will also use more page layouts to report the related content (Figure 1). The SARS issue appeared on the front page more than half study period: the United Daily News is 63 days, the China Post 62 days and the Liberty Times 70 days, respectively.

\subsection{Distribution of Contents}

In the reporting contents, the three newspapers mainly emphasized the "Impact" dimension (34.27\%), including the economic impact of SARS, especially for tourism and aviation industry. Social impact focused on discussion of medical ethics and the role of health care professionals. Legal impact focused on not only the laws and regulations enacted by SARS, but also the inconvenience and controversy toward people's lives caused by the enforcement of the law. 


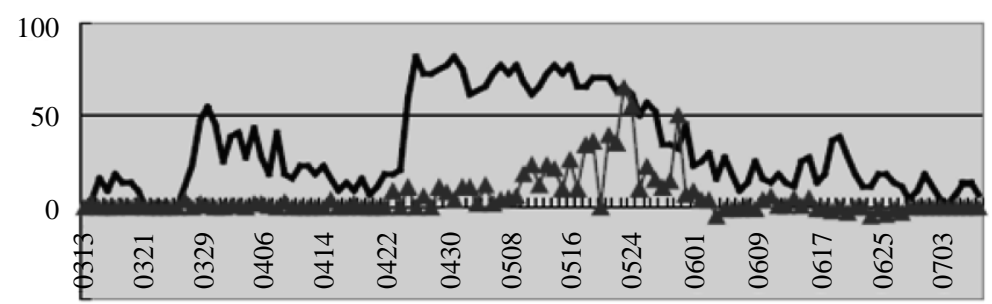

(a)

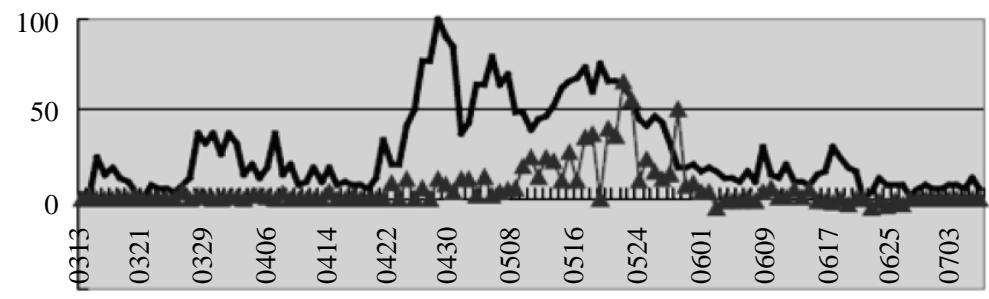

(b)

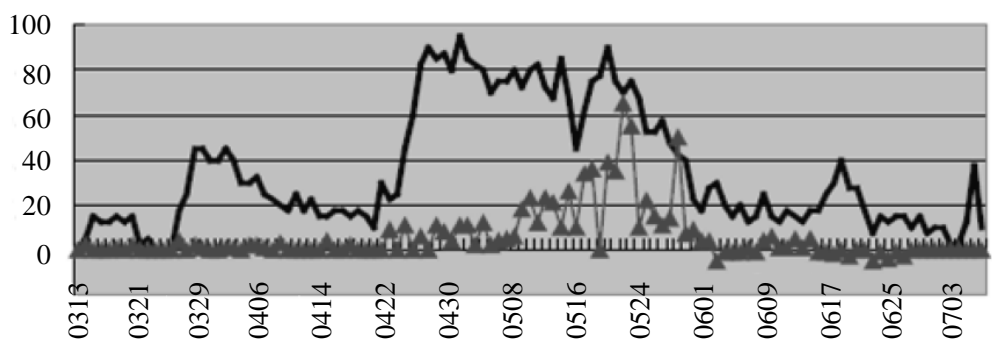

(c)

Layout occupying rate (\%) - $\longrightarrow$ epidemic development (case)

Figure 1. The trend of SARS epidemic development and news layout occupying rate. (a) United Daily News, (b) China Post, (c) Liberty Times.

"Control measures" is the next focus dimension (23.46\%), including the introduction of related quarantine and isolation measures and the problems of allocating resources (such as masks, negative pressure rooms establishment). However, only $2.16 \%$ of the coverage was on the topic of health communication and prevention education. There were significant differences in the contents $\left.\chi^{2}=541.55, \mathrm{p}<0.05\right)$ of reporting the "SARS event" in those three newspapers (Table 1).

\subsection{Sources of Information}

Overall, the opinions of general public are the primary sources of news (46.57\%), followed by foreign news reports (15.02\%), and central ministries (14.71\%). The media adopted health related experts as sources only occupying 7.40\%. Health authority (i.e., Department of Health) was not the main and typical sources of information (9.42\%). The sources quoted in reporting "SARS event" were significant differences in the three newspapers $\left(\chi^{2}=174.73, \mathrm{p}<0.05\right)$ (Table 2).

\section{Discussion}

In the present study, we found that the layout and amount of printed SARS-related news had been increasing in accordance with the development of SARS epidemic. It demonstrates that media will increase the coverage proportion and frequency in the front page when they recognized it as a hot issue. As you can see from Figure 1, the amount of related news seems to occur earlier than dramatic cases had generated. We argue it probably because the transmission of disease has step into nosocomial infection. Several hospitals are forced closure temporarily and all patients, visitors and staff were isolated in the hospital buildings. These triggered media discussion of related issues, such as ethical issues of professional healthcare staff, patient right, justification of hospital 
Table 1. Distribution of the reporting contents.

\begin{tabular}{cccccccc}
\hline \multirow{2}{*}{ Dimensions } & \multicolumn{2}{c}{ United Daily News } & \multicolumn{2}{c}{ China Post } & \multicolumn{2}{c}{ Liberty Times } & $\chi^{2}$ \\
\cline { 2 - 6 } & $\mathrm{n}^{\mathrm{a}}$ & $\%$ & $\mathrm{n}^{\mathrm{a}}$ & $\%$ & $\mathrm{n}^{\mathrm{a}}$ & $\%$ & \\
\hline International interaction & 565 & 18.29 & 597 & 21.31 & 364 & 12.00 & \\
Epidemic message & 241 & 7.80 & 292 & 10.42 & 300 & 9.89 & \\
Control measures & 818 & 26.48 & 536 & 19.14 & 740 & 24.39 & $541.55^{*}$ \\
Impact & 1059 & 34.29 & 928 & 33.13 & 1071 & 35.30 & \\
Others & 405 & 13.11 & 448 & 15.99 & 559 & 18.42 & \\
Total & 3088 & 100.00 & 2801 & 100.00 & 3034 & 100.00 \\
\hline
\end{tabular}

a news article; ${ }^{*} \mathrm{p}<0.05$.

Table 2. Distribution of the quoted source for information.

\begin{tabular}{|c|c|c|c|c|c|c|c|}
\hline \multirow{2}{*}{ Sources } & \multicolumn{2}{|c|}{ United Daily News } & \multicolumn{2}{|c|}{ China Post } & \multicolumn{2}{|c|}{ Liberty Times } & \multirow{2}{*}{$\chi^{2}$} \\
\hline & $\mathrm{n}^{\mathrm{a}}$ & $\%$ & $\mathrm{n}^{\mathrm{a}}$ & $\%$ & $\mathrm{n}^{\mathrm{a}}$ & $\%$ & \\
\hline Health authorities & 286 & 9.27 & 241 & 8.61 & 313 & 10.32 & \multirow{7}{*}{$174.73^{*}$} \\
\hline Local government $^{1}$ & 229 & 7.43 & 185 & 6.61 & 193 & 6.37 & \\
\hline Central ministries $^{2}$ & 435 & 14.11 & 357 & 12.73 & 520 & 17.15 & \\
\hline Health experts ${ }^{3}$ & 269 & 8.72 & 221 & 7.90 & 174 & 5.74 & \\
\hline General public & 1337 & 43.35 & 1263 & 45.14 & 1552 & 51.19 & \\
\hline Foreign reports & 528 & 17.12 & 531 & 18.98 & 280 & 9.23 & \\
\hline Total $^{\mathrm{b}}$ & 3084 & 100.00 & 2798 & 100.00 & 3032 & 100.00 & \\
\hline
\end{tabular}

${ }^{a}$ news article; ${ }^{b}$ not include news which were not quoted the information source. ${ }^{1}$ refers to county governments and their institutions; ${ }^{2}$ including the Executive Yuan, Legislative Yuan, Judicial Yuan, Examination Yuan and Control Yuan, the Ministry of Education and their respective ministries and departments (excluding the Department of Health); ${ }^{3}$ refers to public health, epidemiology, health policy, hospital management, infection control, disease research related to this subject experts and scholars. ${ }^{*} \mathrm{p}<0.05$.

closure. However, it takes times to confirm whether the patient is suffering from SARS. Thus, there is a time lag between reports and epidemic.

In order to enhance broadcast popularity, media usually select news to report based on public preference or interests. Thus, the three newspapers mainly emphasized the "Impact" dimension. Those reports related to health education topics seem not to catch media's attention. It is perhaps due to editors took the newsworthiness as higher priority when selecting news for publication rather than social responsibility. Thus, base on the finding, we recommend that government agencies may need to appropriate funds routinely to the media for health education propaganda. Health authority may use it to convey preventive messages to public during the halcyon days, and transmit the rules or regulations requiring public to abide by in such pandemics strike.

Health authority and health experts were not the main and typical sources of news reports. Consequently, parts of baseless, specious, false news, or report without governmental confirmation may spread out. These may raise the public unnecessarily panic, additional burden for the government to manage the false news, and also undermines credibility of the media. Therefore, we suggest the health authority should establish a professional, unitary spokesman mechanism to delivery correct and prompt information to the media and the public. Transparency information is the only way to get the trust of the public [24]. In addition, newsman should cultivate their professional capabilities, verify the correctness of source information and stick to the industry code of ethics to deliver the quality of news report during the outbreaks of infectious diseases or a major disaster. Furthermore, according to Article 63 of the Control of Communicable Disease Act in Taiwan, spreading false rumors or news of epidemic of communicable diseases will be fined maximum of NT 500,000. We recommend that reporters should double check with official information before publish it. We also suggest that medical reporters should receive continuing education hours per year on related knowledge of communicable diseases.

Despite we found there were more positive reports than negative ones in three newspapers (not shown), several survey indicated that media is the arch-criminal in creating the social panic during the SARS epidemic [12] 
[25]. The possible reasons might be that a group's psychological discomfort influenced by negative reports is profound even in small quantities. In addition, the media will produce the so-called amplification [26], which can produce consequential "ripples" effect spreading far beyond the risk event's initial impact. Further, everyone interprets the message differently due to their personal values, norms, experiences, or social status [27]-[29]. Those considerations remind that the media have to weigh the pros and cons of provocative title more carefully and morally. Public should cultivate media literacy to enhance their judgment of messages conveyed by media.

Several study limitations must be mentioned. First, we only selected three leading influential newspapers for content analysis due to time and manpower constraints. However, access to source information is changing nowadays, especially thanks to the internet with quick updating feature. Future research may include other electronic newspapers or television into analysis to explore the difference between different media format. Second, the categorization process will be inevitably influenced by subjective perception or personal experience. Third, the findings can only present the frequency or changes in quantity, unable to measure the impact of media on the disease control.

\section{Conclusion}

Risk communication is the most important part during the crisis management [30]. The media is a major source from which people perceive risk in the initial stage, thus, it plays an important role in pandemics events [31] [32]. The study results suggest that the educational function of the media needs to be strengthened, especially in public health issue. Thus, health authority should construct mechanisms to cooperate with the media. Using its properties which can rapidly transmit message to mass audiences to inform risk related knowledge before the crisis, to convey how to avoid the potential damage in times of crisis, and to remind follow-up preventative measures or newly perception of risk after the crisis. Media is a double-edged sword in the communicable disease control. However, if you use it well, you can turn a stumbling block into a stepping stone.

\section{Competing Interests}

None declared.

\section{Ethical Approval}

Not required.

\section{References}

[1] Schramm, W.L. (1957) Responsibility in Mass Communication. Harper, New York.

[2] Stevens, R. and Hornik, R.C. (2014) AIDS in Black and White: The Influence of Newspaper Coverage of HIV/AIDS on HIV/AIDS Testing Among African Americans and White Americans, 1993-2007. Journal of Health Communication. http://dx.doi.org/10.1080/10810730.2013.864730

[3] Sepúlveda Amor, J., Fineberg, H.V. and Mann, J.M. (1992) AIDS: Prevention through Education: A World View. Oxford University Press, New York.

[4] Hung, R. (2012) A Research on the Impact of Social Media on Taiwan’s Health Communication. Shih Hsin University, Taipei.

[5] Gooding, S.K. (1995) The Relative Importance of Information Sources in Consumers' Choice of Hospitals. Journal of Ambulatory Care Marketing, 6, 99-108. http://dx.doi.org/10.1300/J273v06n01 07

[6] Gao, J., Fu, H., Lin, L., Nehl, E.J., Wong, F.Y. and Zheng, P. (2013) Newspaper Coverage of HIV/AIDS in China from 2000 to 2010. AIDS Care, 25, 1174-1178. http://dx.doi.org/10.1080/09540121.2012.752785

[7] Chan, C.-Y. (2013) Health Information Needs and Seeking Behavior of Patients, and How Do They Choose Physicians. National Tsing Hua University, Hsinchu.

[8] Backer, T.E., Rogers, E.M. and Sopory, P. (1992) Designing Health Communication Campaigns: What Works? Sage, Newbury Park. http://dx.doi.org/10.4135/9781483325521

[9] Summary of Probable SARS Cases with Onset of Illness. http://www.who.int/csr/sars/country/table2004_04_21/en/

[10] Yeh, S.H., Wang, H.Y., Tsai, C.Y., Kao, C.L., Yang, J.Y., Liu, H.W., Su, I.J., Tsai, S.F., Chen, D.S. and Chen, P.J. (2004) Characterization of Severe Acute Respiratory Syndrome Coronavirus Genomes in Taiwan: Molecular Epidemiology and Genome Evolution. Proceedings of the National Academy of Sciences of the USA, 101, 2542-2547. 
http://dx.doi.org/10.1073/pnas.0307904100

[11] Knudsen, A.K., Omenas, A.N., Harvey, S.B., Lovvik, C.M., Lervik, L.V. and Mykletun, A. (2011) Chronic Fatigue Syndrome in the Media: A Content Analysis of Newspaper Articles. JRSM Open, 2, 42. http://dx.doi.org/10.1258/shorts.2011.011016

[12] Lyu, S.-Y., Peng, E.Y.-C. and Shih, F.-Y. (2007) Public Perception of Media Reporting during the Severe Acute Respiratory Syndrome Outbreak in Taiwan. Taipei City Medical Journal, 4, 668-679.

[13] Yeh, C.-N. and Hsu, W.-P. (2006) Evaluating Crisis Management of Taiwan's Government in Terms of Newspapers: A Case Study of SARS. The Journal of Chinese Public Administration, 3, 59-82.

[14] Peng, E.Y., Lee, M.B., Tsai, S.T., Yang, C.C., Morisky, D.E., Tsai, L.T., Weng, Y.L. and Lyu, S.Y. (2010) Population-Based Post-Crisis Psychological Distress: An Example from the SARS Outbreak in Taiwan. Journal of the Formosan Medical Association, 109, 524-532. http://dx.doi.org/10.1016/S0929-6646(10)60087-3

[15] Cole, F.L. (1988) Content Analysis: Process and Application. Clinical Nurse Specialist, 2, 53-57. http://dx.doi.org/10.1097/00002800-198800210-00025

[16] Elo, S. and Kyngäs, H. (2008) The Qualitative Content Analysis Process. Journal of Advanced Nursing, 62, 107-115. http://dx.doi.org/10.1111/j.1365-2648.2007.04569.x

[17] Graneheim, U.H. and Lundman, B. (2004) Qualitative Content Analysis in Nursing Research: Concepts, Procedures and Measures to Achieve Trustworthiness. Nurse Education Today, 24, 105-112. http://dx.doi.org/10.1016/j.nedt.2003.10.001

[18] Content Analysis: A Methodology for Structuring and Analyzing Written Material. http://www.gao.gov/products/PEMD-10.3.1

[19] Schafferer, C. (2004) Content Analysis of Newspaper and Television Advertisements: A Case Study of Taiwan’s 2004 Presidential Election. Modern East Asia, 3, 1-19.

[20] Duncan, D.F. (1989) Content Analysis in Health Education Research: An Introduction to Purposes and Methods. Health Education, 20, 27-31.

[21] Neuendorf, K.A. (2002) The Content Analysis Guidebook. Sage Publications Inc., California.

[22] Fleiss, J. (1981) Statistical Methods for Rates and Proportions. John Wiley and Sons, New York.

[23] Lombard, M., Snyder-Duch, J. and Bracken, C.C. (2002) Content Analysis in Mass Communication: Assessment and Reporting of Intercoder Reliability. Human Communication Research, 28, 587-604. http://dx.doi.org/10.1111/j.1468-2958.2002.tb00826.x

[24] Menon, K.U. and Goh, K.T. (2005) Transparency and Trust: Risk Communications and the Singapore Experience in Managing SARS. Journal of Communication Management, 9, 375-383. http://dx.doi.org/10.1108/13632540510621614

[25] Wu, Y.-C. (2004) An Examination on Crisis Communication Responses and Campaign Strategies during and Post the SARS Outbreak: A Taiwan's Case. Prospect Quarterly, 5, 107-150.

[26] Kasperson, R.E., Renn, O., Slovic, P., Brown, H.S., Emel, J., Goble, R., Kasperson, J.X. and Ratick, S. (1988) The Social Amplification of Risk: A Conceptual Framework. Risk Analysis, 8, 177-187. http://dx.doi.org/10.1111/j.1539-6924.1988.tb01168.x

[27] Gustafson, P.E. (1998) Gender Differences in Risk Perception: Theoretical and Methodological Perspectives. Risk Analysis, 18, 805-811. http://dx.doi.org/10.1023/B:RIAN.0000005926.03250.c0

[28] Willis, H.H. and Dekay, M.L. (2007) The Roles of Group Membership, Beliefs, and Norms in Ecological Risk Perception. Risk Analysis, 27, 1365-1380. http://dx.doi.org/10.1111/j.1539-6924.2007.00958.x

[29] Slimak, M.W. and Dietz, T. (2006) Personal Values, Beliefs, and Ecological Risk Perception. Risk Analysis, 26, 16891705. http://dx.doi.org/10.1111/j.1539-6924.2006.00832.x

[30] Seeger, M.W., Sellnow, T.L. and Ulmer, R.R. (1998) Communication, Organization and Crisis. In: Roloff, M.E., Ed., Communication Yearbook 21, Greenwood Publishing Group.

[31] Singer, E. and Endreny, P.M. (1993) Reporting on Risk: How the Mass Media Portray Accidents, Diseases, Disasters, and Other Hazards. Russell Sage Foundation.

[32] Yeh, N.-C. (2003) Citizens' Health Information Behaviors during SARS Spread Periods in Taiwan. Journal of Library and Information Studies, 1, 95-110. 
Scientific Research Publishing (SCIRP) is one of the largest Open Access journal publishers. It is currently publishing more than 200 open access, online, peer-reviewed journals covering a wide range of academic disciplines. SCIRP serves the worldwide academic communities and contributes to the progress and application of science with its publication.

Other selected journals from SCIRP are listed as below. Submit your manuscript to us via either submit@scirp.org or Online Submission Portal.
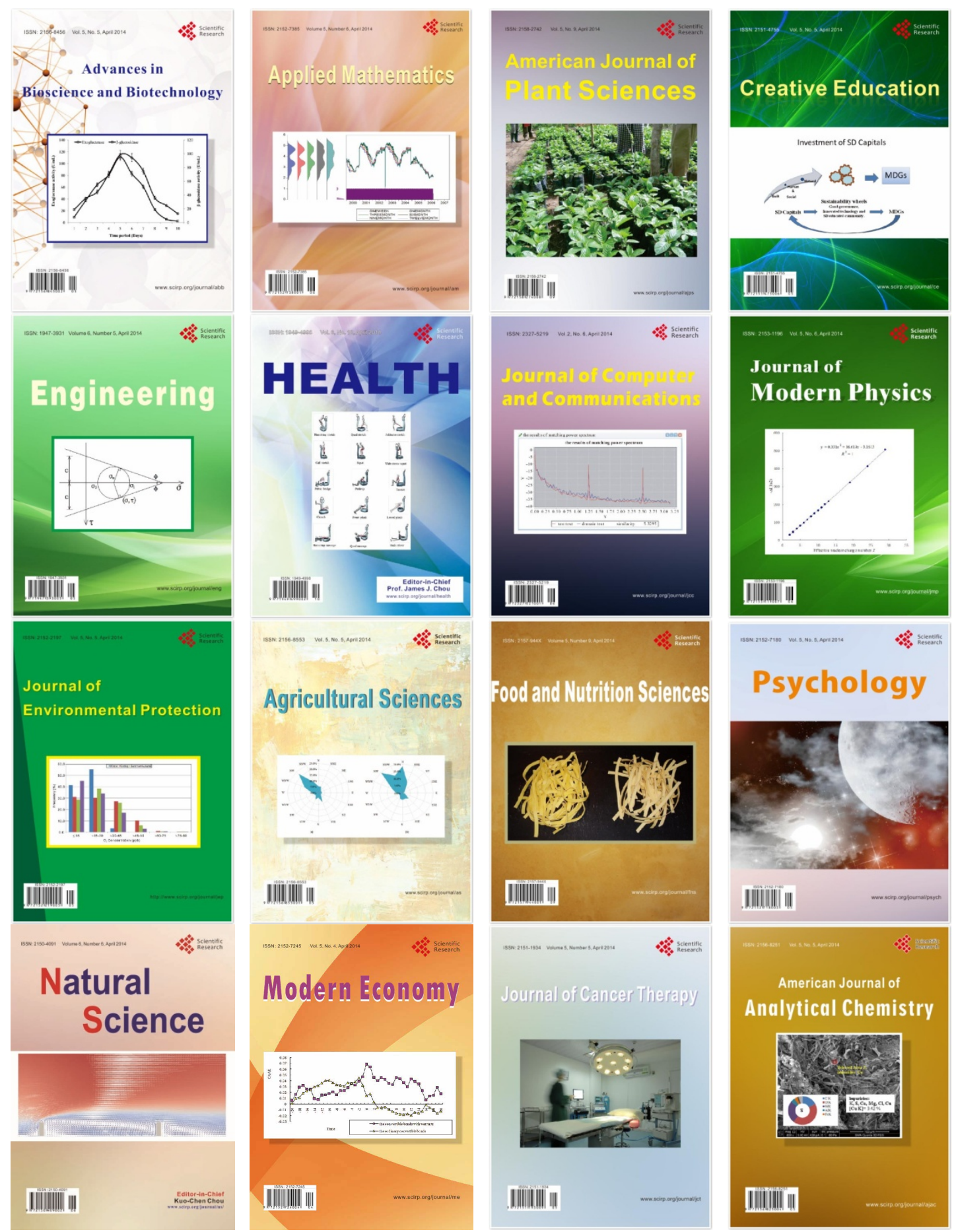